\title{
Correction to: Temperate forest fragments maintain aboveground carbon stocks out to the forest edge despite changes in community composition
}

\author{
Carly Ziter $^{1} \cdot$ Elena M. Bennett ${ }^{2} \cdot$ Andrew Gonzalez $^{1}$
}

Published online: 6 June 2021

(c) Springer-Verlag GmbH Germany, part of Springer Nature 2021

\section{Correction to: Oecologia (2014) 176:893-902 \\ https://doi.org/10.1007/s00442-014-3061-0}

The error resulted in an incorrect calculation of carbon in downed woody debris, which affected the total aboveground carbon stocks reported in the paper. The changes to the paper are extremely minor, involving a quantitative change to one result, detailed below, as well as one updated figure panel (attached).

Correction: Aboveground carbon stocks remained constant over the distance gradient, with no effect of proximity to the forest edge on AGC stocks $\left(\chi^{2}(1)=0.0041, P=0.95\right)$ (Fig. 2a).

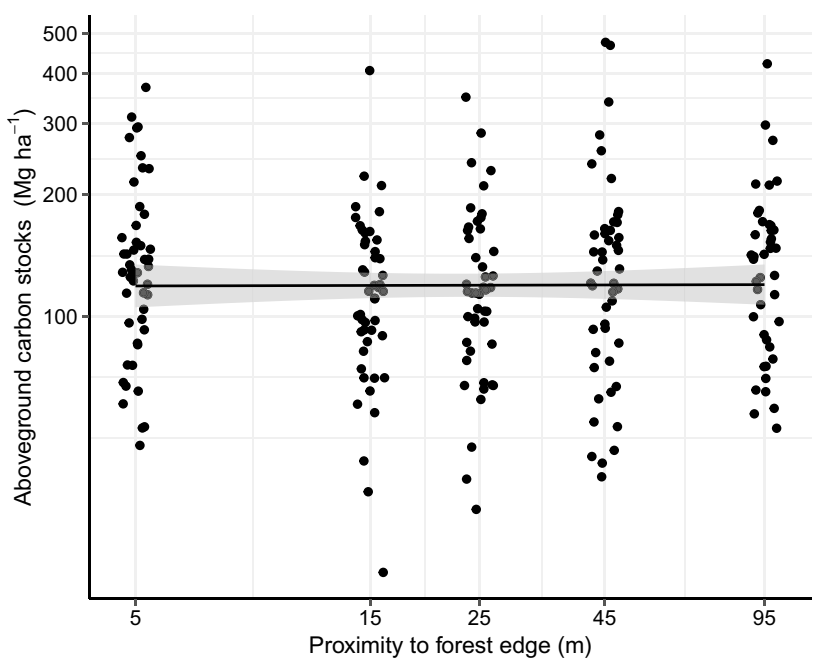

The original article can be found online at https://doi.org/10.1007/ s00442-014-3061-0.

Carly Ziter

carly.ziter@mail.mcgill.ca

Elena M. Bennett

elena.bennett@mcgill.ca

Andrew Gonzalez

andrew.gonzalez@mcgill.ca

1 Department of Biology, McGill University, 1205 Docteur

Penfield, Montreal, QC H3A 1B1, Canada

2 Department of Natural Resource Sciences and McGill School of Environment, McGill University, 21, 111 Lakeshore Road, Sainte-Anne-de-Bellevue, Montreal, QC H9X 3V9, Canada 